\title{
Alternativas para o controle de odores e corrosão em sistemas de coleta e tratamento de esgoto
}

\author{
Alternatives to odor and corrosion control in \\ sanitary sewerage systems and treatment plants
}

Emanuel Manfred Freire Brandt', Cláudio Leite Souza², Carlos Augusto Lemos Chernicharo ${ }^{3}$

口-

\begin{abstract}
RESUMO
Este artigo busca consolidar as principais características, vantagens e desvantagens de métodos disponíveis no meio técnico e científico para o controle de odores e corrosão em redes coletoras e estações de tratamento de esgoto, trazendo uma abordagem atualizada sobre soluções preventivas relacionadas à concepção eà operação de sistemas deesgotamento, comadição de compostos químicos ou aeração em fase líquida. São apresentados os princípios de cada técnica e consolidadas as principais diretrizes para o projeto de alternativas. Além disso, são apresentadas diretrizes para a concepção de soluções corretivas com contenção e exaustão de unidades/fontes potencialmente odorantes, incluindo uma discussão sobre os processos atualmente disponíveis no meio técnicocientífico para tratamento de gases odorantes e corrosivos.
\end{abstract}

Palavras-chave: sulfeto de hidrogênio; aeração; oxidação química; precipitação de sulfeto.

\begin{abstract}
This paper aims to consolidating the main characteristics, advantages and disadvantages of available methods in technical-scientific community to odor and corrosion control in sanitary sewerage systems and treatment plants, taking along an innovative approach on preventive solutions related to sewage systems design and operation with addition of chemicals or liquid phase aeration. The main beliefs of each technique are presented as well as the main guidelines for alternatives design. In addition, guidelines are given for corrective solutions design of covers and exhaust of potentially odorous sources, as well as a brief discussion of processes currently available in the technical-scientific community to the treatment of odorant odorous and corrosive gases.
\end{abstract}

Keywords: hydrogen sulfide; aeration; chemical oxidation; sulfur precipitation.

\section{INTRODUÇÃO}

A emissão de gases odorantes em unidades de coleta, transporte e tratamento de esgoto sanitário (ETEs) é tradicionalmente um aspecto ambiental negativo relevante, que compromete o desempenho socioambiental de empreendimentos do setor de saneamento e conduz a uma cultura de repúdio à implantação de novas ETEs em áreas urbanas. Muitas vezes, as queixas da população são advindas dos odores que escapam das redes de esgoto, contudo, mais frequentemente, os incômodos são provocados nas vizinhanças de estações elevatórias e de tratamento de esgoto (BOON; VINCENT; BOON, 1998; USEPA, 1985). Somada a essas questões, a corrosão acelerada de peças e estruturas, causada pela natureza agressiva de alguns gases odorantes, leva à necessidade de um adequado gerenciamento desse aspecto ambiental (WERF, 2007). Em reatores anaeróbios utilizados para o tratamento de esgoto, a emissão de gases odorantes é uma questão de grande importância que, se não for tratada adequadamente, poderá prejudicar a aplicação mais ampla da tecnologia no Brasil.

No caso do esgoto doméstico, a decomposição anaeróbia de compostos de enxofre é a principal causa da geração de odores. Dependendo do composto precursor, do $\mathrm{pH}$ e do potencial de oxirredução do esgoto, diferentes compostos odorantes são biologicamente formados, sendo o sulfeto de hidrogênio $\left(\mathrm{H}_{2} \mathrm{~S}\right)$, resultante da redução biológica do sulfato $\left(\mathrm{SO}_{4}^{2-}\right)$ ou tiossulfato $\left(\mathrm{S}_{2} \mathrm{O}_{3}{ }^{2-}\right)$ pelas bactérias redutoras de sulfato (BRS), o composto mais comumente associado aos odores do esgoto, embora outros compostos de enxofre (Ex.: mercaptanas), ácidos orgânicos voláteis, alcoóis e amônia também possam contribuir para a percepção dos odores provenientes do esgoto (STUETZ \& FRECHEN, 2001). As espécies do sulfeto dissolvido se difundem no esgoto a partir da biomassa,

\footnotetext{
'Professor adjunto do Departamento de Engenharia Sanitária e Ambiental (DESA) da Universidade Federal de Juiz de Fora (UFJF) - Juiz de Fora (MG), Brasil. 2Professor adjunto do DESA da Universidade Federal de Minas Gerais (UFMG) - Belo Horizonte (MG), Brasil. ${ }^{3}$ Professor titular do DESA da UFMG - Belo Horizonte (MG), Brasil.

Endereço para correspondência: Emanuel Manfred Freire Brandt - Universidade Federal de Juiz de Fora - Faculdade de Engenharia - Departamento de Engenharia Sanitária e Ambiental - Rua José Lourenço Kelmer, s/n - Martelos - 36036-330 - Juiz de Fora (MG), Brasil - E-mail: emanuel.brandt@ufjf.edu.br Recebido em: 28/01/15 - Aceito em: 12/08/16 - Reg. ABES: 145398
} 
em que podem ser encontras na forma ionizada (o bissulfeto - $\mathrm{HS}_{(\mathrm{aq})}^{-}$ e o sulfeto - $\mathrm{S}_{(\mathrm{aq})}^{2-}$ ) ou associada ao hidrogênio $\left(\mathrm{o}_{2} \mathrm{~S}_{(\mathrm{aq})}\right)$, a depender do $\mathrm{pH}$ do meio (PARK et al., 2014). No pH típico do esgoto (6.5 a 8.5), $\mathrm{o} \mathrm{H}_{2} \mathrm{~S}_{(\text {aq) }}$ e o HS ${ }_{(\text {aq) }}$ são as espécies dominantes, sendo que o odor característico é formado a partir do desprendimento do $\mathrm{H}_{2} \mathrm{~S}_{(\mathrm{g})}$ para a atmosfera, levando a concentrações de até $400 \mathrm{ppm}_{\mathrm{v}}$ no interior dos dutos de coleta de esgoto (JOBBAGY et al., 1994; MATOS \& AIRES, $1995)$ e até $500 \mathrm{ppm}_{\mathrm{v}}$ nas atmosferas gasosas imediatas existentes em estações elevatórias e de tratamento de esgoto (AL-SHAMMIRI, 2004; BOHN, 1993; PAGLIUSO; PASSIG; VILLELA, 2002; SILVA et al., 2007; SOUZA, 2010; SOUZA; CHERNICHARO; MELO, 2010).

Considerando a relevância do tema, o principal objetivo deste artigo é apresentar alternativas para minimizar a geração de odores em unidades de coleta, transporte e tratamento de esgoto, trazendo uma abordagem atualizada sobre a concepção e a operação de sistemas de esgotamento e sobre os processos de tratamento químico do esgoto bruto. Apesar dos esforços que venham a se desenvolver no sentido de minimizar a ocorrência de odores nas unidades de coleta, transporte e tratamento de esgoto, é esperado que ocasionalmente eles ocorram e causem incômodos ou problemas de corrosão (METCALF \& EDDY \& TCHOBANOGLOUS, 2014). Dessa forma, também é objetivo deste artigo apresentar diretrizes para a concepção de coberturas/contenção e exaustão de unidades potencialmente odorantes, incluindo uma breve discussão sobre os processos atualmente disponíveis no meio técnico-científico para o tratamento de gases odorantes.

\section{MEDIDAS PREVENTIVAS: MINIMIZAÇÃO DE EMISSÕES ODORANTES}

Os esforços para a minimização de emissões odorantes devem ocorrer já na concepção dos sistemas de coleta e transporte de esgoto, por meio da correta quantificação das vazões e cargas de esgoto, do dimensionamento hidráulico apropriado do sistema, da minimização do comprimento das tubulações de recalque, quedas hidráulicas e volumes dos poços de sucção, e da concepção de alternativas para facilitar as operações de limpeza do sistema (ASCE, 1995; PARK et al., 2014; STUETZ \& FRECHEN, 2001; WEF, 1995). Na concepção de ETEs, às considerações anteriores se acresce a preocupação com o escoamento em regime turbulento dos fluxos potencialmente odorantes (linhas de retorno das operações de espessamento e de desidratação de lodo ou pontos de recepção de lodo de tanques sépticos), devendo-se optar por entradas submersas em vez de quedas hidráulicas; e a prevenção da deposição de sólidos e do estabelecimento de zonas com gradientes de velocidade baixos ou nulos (METCALF \& EDDY \& TCHOBANOGLOUS, 2014; USEPA, 1985). Alternativamente, pode-se pensar de maneira inversa, tirando proveito do escoamento em regime turbulento e das descargas não afogadas, maximizando a geração de emissões odorantes, desde que restritas a locais planejados, confinados, equipados com dispositivos de exaustão e com fluxo gasoso encaminhado para tratamento dos gases. Tal alternativa é contemplada no item de medidas corretivas.

Já na operação dos sistemas de esgotamento sanitário, diversas estratégias podem ser adotadas para a minimização da geração de odores, que vão desde restrições a descargas que contenham compostos odorantes ou que induzam o estabelecimento de condições anaeróbias e a formação de compostos odorantes (DE HEYDER \& THOEYE, 2000), até a adição de produtos químicos ao esgoto bruto ou a uma determinada corrente líquida/sólida do processo de tratamento, que oxidam ou precipitam os sulfetos em geral, ou ionizam o $\mathrm{H}_{2} \mathrm{~S}_{(\mathrm{aq})}\left(\mathrm{HS}^{-}, \mathrm{S}^{2-}\right)$ impedindo a sua liberação para a fase gasosa, como $\mathrm{H}_{2} \mathrm{~S}_{(\mathrm{g})}$; ou a introdução de $\operatorname{ar}\left(\right.$ aeração)/oxigênio $\left(\mathrm{O}_{2}\right)$ ou nitrato à fase líquida, que alteram o potencial de oxirredução do meio e fornecem condições específicas para a inibição das BRS e o desenvolvimento de microrganismos oxidadores de sulfetos (AUGUET et al., 2015; WERF, 2007). Nas seções subsequentes, são apresentados maiores detalhes sobre as estratégias de adição de produtos químicos ou aeração de correntes líquidas/sólidas dos sistemas de coleta e tratamento de esgoto.

\section{Adição de sais de nitrato}

$\mathrm{O}$ controle da emissão/desprendimento de $\mathrm{H}_{2} \mathrm{~S}$ pela adição de nitrato $\left(\mathrm{NO}_{3}{ }^{-}\right)$ocorre por meio de dois mecanismos (AUGUET et al., 2015; JIANG; SHARMA; YUAN, 2013; ZHANG et al., 2008):

1. favorecimento da atividade de microrganismos quimiolitotróficos (Ex.: Thiobaccillus denitrificans), capazes de oxidar os sulfetos (Ex.: HS $)$ a enxofre elementar $\left(\mathrm{S}^{0}\right)$ ou $\mathrm{SO}_{4}^{-}$e reduzir o $\mathrm{NO}_{3}$ a nitrito $\left(\mathrm{NO}_{2}^{-}\right)$ou nitrogênio gasoso $\left(\mathrm{N}_{2}\right)$, de acordo com as Equações 1 a 4;

2. desenvolvimento de bactérias heterotróficas redutoras de nitrato (desnitrificantes), que competem com as BRS pela utilização da matéria orgânica como fonte de elétrons.

$\mathrm{HS}^{-}+\mathrm{NO}_{3}^{-}+\mathrm{H}^{+} \rightarrow \mathrm{S}^{0}+\mathrm{NO}_{2}^{-}+\mathrm{H}_{2} \mathrm{O}$

$\mathrm{HS}^{-}+0,4 \mathrm{NO}_{3}^{-}+1,4 \mathrm{H}^{+} \rightarrow \mathrm{S}^{0}+0,2 \mathrm{~N}_{2}+1,2 \mathrm{H}_{2} \mathrm{O}$

$\mathrm{S}^{0}+3 \mathrm{NO}_{3}^{-}+\mathrm{H}_{2} \mathrm{O}+3 \mathrm{H}^{+} \rightarrow \mathrm{SO}_{4}^{2-}+3 \mathrm{NO}_{2}^{-}+5 \mathrm{H}^{+}$

$\mathrm{S}^{0}+1,2 \mathrm{NO}_{3}^{-}+0,4 \mathrm{H}_{2} \mathrm{O}+1,2 \mathrm{H}^{+} \rightarrow \mathrm{SO}_{4}{ }^{2-}+0,6 \mathrm{~N}_{2}+2 \mathrm{H}^{+}$

Com relação às equações de oxidação do HS apresentadas anteriormente, estudos revelaram o $S^{0}$ como principal produto formado em condições anóxicas, quando o $\mathrm{NO}_{3}{ }^{-}$é o aceptor de elétrons (Equações 1 e 2). Nessas condições, a formação do $\mathrm{SO}_{4}{ }^{2-}$ deve ocorrer somente quando as concentrações de HS- forem desprezíveis (Equações 3 e 4) (NIELSEN; HVITVED-JACOBSEN; VOLLERTSEN, 2005; NIELSEN; VOLLERTSEN; HVITVED-JACOBSEN, 2003; YANG; VOLLERTSEN; HVITVED-JACOBSEN, 2005).

Para o controle de odores, normalmente $\mathrm{o}_{3}{ }^{-}$é adicionado em estações elevatórias, a montante de ETEs (nos canais principais ou, 
se for o caso, nas linhas de recalque), ou também pode se usado no processo de desaguamento de lodo (AUGUET et al., 2015; EINARSEN et al., 2000; GANIGUE et al., 2011; WERF, 2007).

$\mathrm{O} \mathrm{NO}_{3}$ - é encontrado comercialmente na forma líquida (soluções entre 40 a $60 \%)$ e sólida, como nitrato de sódio $\left(\mathrm{NaNO}_{3}\right)$ ou, mais comumente, como nitrato de cálcio $\left(\mathrm{Ca}\left(\mathrm{NO}_{3}\right)_{2}\right)$. Ele também pode ser produzido em ETEs pelas bactérias nitrificantes e, dessa forma, efluentes de processos de tratamento de esgoto que incluam a nitrificação podem ser utilizados no controle da formação de $\mathrm{H}_{2} \mathrm{~S}$ em outras etapas do tratamento (DELGADO et al., 2004; WERF, 2007). No Brasil, a técnica vem sendo aplicada com sucesso pela Companhia de Saneamento Básico do Estado de São Paulo (SABESP), por meio da adição de nitrato de amônio $\left(\mathrm{NH}_{4} \mathrm{NO}_{3}\right)$ em pontos estratégicos das redes coletoras de esgotos, das estações elevatórias e das ETEs das cidades de Santos e São Vicente no Litoral Paulista, e Monte Prazível no interior de São Paulo (AZEVEDO et al., 1993; LILIAMTIS, 2007; ROSSIN et al., 1989).

A demanda teórica de $\mathrm{NO}_{3}$ - para a oxidação dos sulfetos a $\mathrm{S}^{0}$ elementar é estimada entre 0,18-0,44 kgN-NO - por kgS, na forma de sulfetos dissolvidos totais (YANG; VOLLERTSEN; HVITVED-JACOBSEN, 2005). Entretanto, considerando a presença de matéria orgânica e espécies iônicas no esgoto, bem como a atividade da biomassa suspensa no meio líquido e aderida ao biofilme formado nas estruturas dos sistemas de coleta e tratamento de esgoto, geralmente são empregadas dosagens da ordem de 9,6 kgN-NO $\mathrm{NO}_{3}$ por $\mathrm{kgS}$ (WEF, 2004), ou 1,3-15,5 kgN-NO a cada $1.000 \mathrm{~m}^{3}$ de esgoto (GANIGUE et al., 2011), embora a literatura também aponte dosagens menores, variando de 0,3 a 4,5 $\mathrm{kgN}^{-\mathrm{NO}_{3}}$ - por $\mathrm{kgS}$ (BENTZEN et al., 1995; EINARSEN et al., 2000; GARCIA DE LOMAS et al., 2006; HOBSON \& YANG, 2000; MOODY \& RIEK, 1999 apud ZHANG et al., 2008; RODRIGUEZ-GOMEZ et al., 2005; WERF, 2007). De qualquer forma, a dosagem requerida pode ser maior ou menor em função das diferentes configurações dos sistemas de coleta e tratamento de esgoto, sendo que os valores reportados anteriormente devem ser utilizados como um ponto de partida para ajustes mais precisos. Em uma experiência prática, Bentzen et al. (1995) reportaram a adição de uma média de $10,0 \mathrm{kgN}-\mathrm{Ca}\left(\mathrm{NO}_{3}\right)_{2} \cdot 1.000 \mathrm{~m}^{-3}$ de esgoto em uma estação elevatória a montante de uma ETE no Reino Unido que tratava uma vazão de esgoto equivalente a $3.700 \mathrm{~m}^{3} \cdot \mathrm{d}^{-1}$, o que garantiu concentrações de $\mathrm{NO}_{3}{ }_{3}^{-}$menores que $2 \mathrm{mg} . \mathrm{L}^{-1}$ na entrada da ETE e reduziu as concentrações de sulfetos no esgoto bruto em $95 \%$. Outras experiências práticas podem ser consultadas em Churchill \& Elmer (1999) e Ganigue et al. (2011).

Mais recentemente, Jiang et al. (2011) e Jiang, Gutierrez e Yuan (2011) revelaram também a importância do efeito biocida do ácido nitroso (forma protonada do $\mathrm{NO}_{2}^{-}$) sobre as BRS existentes em biofilmes formados nas superfícies das estruturas dos sistemas de coleta e tratamento de esgoto. Segundo os autores, o efeito biocida também exerce papel-chave no controle da formação de sulfetos pela adição de $\mathrm{NO}_{2}^{-}$ao esgoto.

\section{Aeração ou oxigenação}

Se o oxigênio dissolvido (OD) estiver presente no esgoto em concentrações superiores a $1,0 \mathrm{mgO}_{2} \cdot \mathrm{L}^{-1}$, além da oxidação química dos sulfetos dissolvidos, ocorrerá o desenvolvimento de bactérias aeróbias suspensas no meio líquido e aderidas às camadas externas do biofilme formado sobre os dutos e estruturas (geralmente até $0,4 \mathrm{~mm}$ de profundidade), as quais são capazes de promover a oxidação biológica das espécies do sulfeto dissolvido que se difundem a partir dos ambientes anaeróbios existentes nas camadas mais profundas da biomassa (PARK et al., 2014; ZHANG et al., 2008).

A introdução de ar ou $\mathrm{O}_{2}$ na massa líquida geralmente é feita em condutos pressurizados, devido à maior solubilidade do $\mathrm{O}_{2}$ em pressões elevadas. Dessa forma, a técnica deve ser aplicada em estações elevatórias ou, preferencialmente, nas linhas de recalque de esgoto bruto (GANIGUE et al., 2011; TANAKA et al., 2000), a fim de garantir concentrações de OD próximas a $1,0 \mathrm{mgO}_{2} / \mathrm{L}$ nas extremidades das tubulações principais de esgoto ou nas entradas das ETEs. A injeção de $\mathrm{O}_{2}$ puro pode elevar as concentrações de OD no esgoto até 5-7 $\mathrm{mgO}_{2} \cdot \mathrm{L}^{-1}$, enquanto que a aeração geralmente induz a uma faixa de $3-5 \mathrm{mgO}_{2} \cdot \mathrm{L}^{-1}$ (CHEN \& LEUNG, 2000; DELGADO et al., 1998). Os seguintes métodos podem ser utilizados para a introdução de ar ou $\mathrm{O}_{2}$ ao fluxo de esgoto, obedecendo, via de regra, a taxas de aeração de 7,9 a 421,3 Lar.h $^{-1} \cdot \mathrm{mm}^{-1}$ de diâmetro da tubulação, ou 0,2 a 6,6 $\mathrm{m}^{3}$ ar. $\mathrm{m}^{-3}$ de esgoto (WERF, 2007):

1. injeção direta de ar em condutos forçados (WEF, 2004);

2. uso de aspiradores do tipo Venturi em derivações do fluxo principal de condutos (HOLDER \& LEOW, 1994);

3. por meio de bombas ou compressores do tipo airlift instalados nas estações elevatórias (USEPA, 1985);

4. uso de câmaras de contato instaladas em derivações do fluxo principal de condutos (MCGINNIS \& LITTLE, 1998); dentre outros.

Diversos autores demonstraram experiências bem sucedidas de injeção de ar em estações elevatórias ou linhas de recalque objetivando a redução da concentração de sulfetos dissolvidos no esgoto bruto afluente a ETEs, atingindo eficiências que variaram de 90 a 100\% (HOLDER \& LEOW, 1994; OCHI; KITAGAWA; TANAKA, 1998; SERCOMBE, 1995; TANAKA \& TAKENAKA, 1995; WERF, 2007). Contudo, em um estudo realizado por Gutierrez et al. (2008), foi observado que a técnica não inativa a comunidade de BRS, que permanece produzindo os sulfetos nas camadas mais profundas do lodo/biofilme. Dessa forma, caso em alguma etapa do tratamento do esgoto as concentrações de OD sejam inferiores a $1,0 \mathrm{mgO}_{2} \cdot \mathrm{L}^{-1}$, ocorrerá um aumento geral na capacidade de produção de sulfetos pela massa líquida, uma vez que o $\mathrm{SO}_{4}^{2-}$ estará presente em concentrações habituais. É importante ressaltar que essa é exatamente a situação que ocorre nos reatores anaeróbios, de uso disseminado no Brasil, aspecto que restringe bastante a aplicação da técnica para o controle de odores nos reatores. Portanto, nesse caso, 
a técnica poderia ser aplicada somente na rede coletora de esgoto ou nas etapas iniciais do tratamento preliminar, ou ainda nos canais dos efluentes dos reatores anaeróbios. Ademais, Gutierrez et al. (2008) alertam que algumas BRS podem tolerar elevadas concentrações de $\mathrm{OD}$, levando à geração de sulfetos também em condições aeróbias.

\section{Adição de oxidantes fortes}

A injeção de $\mathrm{O}_{2}$ ou a simples aeração de fato promovem ambas as oxidações, a química e a biológica. No entanto, há compostos químicos que são oxidantes fortes frequentemente utilizados para reagir com os compostos causadores de odor e corrosão e transformá-los por meio de reações de oxirredução. A aplicabilidade dos diferentes oxidantes químicos no controle da emissão de odores, no entanto, depende de vários fatores, incluindo o potencial de oxirredução do esgoto (valores menores que -100 mV possibilitam a aplicação de técnicas de oxidação química), o tempo de reação, o custo/disponibilidade dos produtos químicos e questões de segurança no manuseio/armazenamento das substâncias (WERF, 2007).

O peróxido de hidrogênio $\left(\mathrm{H}_{2} \mathrm{O}_{2}\right)$ é um exemplo de oxidante forte que reage com compostos reduzidos existentes no esgoto, incluindo as espécies de sulfetos dissolvidos (Ex.: HS'). A principal vantagem da utilização desse oxidante é que, além de oxidar os sulfetos, ele se decompõe em $\mathrm{H}_{2} \mathrm{O}_{\text {e }} \mathrm{O}_{2}$, fornecendo condições para a formação de uma camada aeróbia na biomassa suspensa no esgoto e aderida aos dutos/ estruturas dos sistemas de coleta e tratamento do esgoto (ver vantagens da aplicação da técnica de aeração/oxigenação na seção anterior). Como o oxidante não é seletivo para a reação com os sulfetos dissolvidos, em geral, a aplicação do $\mathrm{H}_{2} \mathrm{O}_{2}$ é feita em excesso, em doses que podem variar de 1,3 a $4,0 \mathrm{kgH}_{2} \mathrm{O}_{2}$ por kgS (TOMAR \& ABDULLAH, 1994; USEPA, 1991; VAN DURME \& BERKENPAS, 1989; WALTRIP \& SNYDER, 1985; ZHANG et al., 2008). Devido à grande amplitude das doses de aplicação do oxidante, recomenda-se fortemente que sejam feitos testes em escala de bancada com amostras reais de esgoto para a determinação da melhor dose a ser aplicada em cada situação. Em média, o oxidante leva aproximadamente 30 minutos para completar toda a reação, sendo que $90 \%$ da reação se completa nos primeiros 10-15 minutos (USEPA, 1985). Por isso, para o controle da emanação de odores em um determinado ponto problemático, pode ser necessária a adição de $\mathrm{H}_{2} \mathrm{O}_{2}$ em vários pontos distantes ao longo da rede coletora de esgoto.

O cloro também é um oxidante que pode ser utilizado para o controle das concentrações de sulfetos dissolvidos no esgoto. Ele pode ser adicionado na forma de solução aquosa (por exemplo, hipoclorito de sódio - $\mathrm{NaClO})$ ou diretamente na forma gasosa $\left(\mathrm{Cl}_{2}\right)$. O cloro possui um longo histórico de eficácia (MOODY \& RIEK, 1999 apud ZHANG et al., 2008; WALTRIP \& SNYDER, 1985; WERF, 2007) e a estrutura necessária para a sua aplicação é amplamente disponível no mercado. Além disso, pode ser aplicado em pontos específicos da rede coletora de esgoto, em estações elevatórias, em linhas de recalque, em etapas específicas do tratamento e em emissários, a despeito de, por questões de segurança, ser tipicamente aplicado dentro dos limites das ETEs (WERF, 2007).

As reações de oxidação dos sulfetos dissolvidos no esgoto pela ação do $\mathrm{Cl}_{2}$ são fortemente dependentes do $\mathrm{pH}$ do meio líquido (Equações 5 e 6) e, estequiometricamente, são necessários $8,6 \mathrm{kgCl}_{2}$ para a oxidação de $1 \mathrm{kgS}$ em condições ácidas ou $2,1 \mathrm{kgCl}_{2}$ para a oxidação de $1 \mathrm{kgS}$ em condições básicas, o que reforça a suscetibilidade das reações ao $\mathrm{pH}$. Na prática, adicionando diretamente na forma gasosa ao esgoto bruto, são recomendadas doses que variam de 4,0 a $15,0 \mathrm{kgCl}_{2}$ por kgS (MOODY \& RIEK, 1999 apud ZHANG et al., 2008; TOMAR \& ABDULLAH, 1994; USEPA, 1985, 1991). No caso da sua aplicação na forma líquida, estequiometricamente são necessários $8,8 \mathrm{kgNaOCl}$ para a oxidação de 1,0 kgS (Equação 7), mas as doses aplicadas também são dependentes do $\mathrm{pH}$ e, na prática, são necessárias doses de 2,0 a 15,0 kgNaOCl por kgS (TOMAR \& ABDULLAH, 1994; USEPA, 1985).

Meio ácido: $\mathrm{HS}^{-}+4 \mathrm{Cl}_{2}+4 \mathrm{H}_{2} \mathrm{O} \rightarrow \mathrm{SO}_{4}^{2-}+9 \mathrm{H}^{+}+8 \mathrm{Cl}^{-}$

Meio básico: $\mathrm{HS}^{-}+\mathrm{Cl}_{2} \rightarrow \mathrm{S}_{0}+\mathrm{H}^{+}+2 \mathrm{Cl}^{-}$

$4 \mathrm{NaOCl}+\mathrm{H}_{2} \mathrm{~S} \rightarrow 4 \mathrm{NaCl}+\mathrm{H}_{2} \mathrm{SO}_{4}$

Assim como o $\mathrm{H}_{2} \mathrm{O}_{2}$, o permanganato - $\mathrm{MnO}_{4}^{-}$(de potássio ou de sódio) é um oxidante forte e também pode ser usado para remoção de sulfetos dissolvidos e de outros compostos causadores de odores, apesar de ser aproximadamente 10 vezes mais caro do que outros oxidantes (ZHANG et al., 2008). O oxidante pode ser obtido na forma de permanganato de potássio $\left(\mathrm{KMnO}_{4}\right)$, comercialmente disponível como um sólido que deve ser dissolvido em água para formar soluções de 3 a $6 \%$, ou na forma de permanganato de sódio $\left(\mathrm{NaMnO}_{4}\right)$, que é vendido em soluções de 12 a 20\%. Para o controle da emissão de odores em ETEs, a USEPA (1991) recomenda a aplicação de dosagens entre 6 e $7 \mathrm{kgKMnO}_{4}$ por $\mathrm{kgS}$, tanto em fluxos líquidos quanto nas etapas de tratamento do lodo gerado em ETEs, sendo particularmente interessante nesse último caso, uma vez que o oxidante reage preferencialmente com as espécies de sulfetos (WERF, 2007).

\section{Adição de sais de ferro}

Vários sais de metais (ferro, zinco, chumbo, cromo, cádmio, níquel e cobre) podem reagir com os sulfetos dissolvidos para formar precipitados relativamente insolúveis ou espécies oxidadas, que evitam o desprendimento de $\mathrm{H}_{2} \mathrm{~S}_{(\mathrm{g})}$ e, consequentemente, a emanação de odores. $\mathrm{O}$ ferro é o metal mais utilizado devido à sua disponibilidade e às restrições ambientais relacionadas ao uso de outros metais. A remoção dos sulfetos dissolvidos em sistemas de coleta e tratamento de esgoto pela adição de sais de ferro é uma das técnicas de controle de odores mais aplicadas e relativamente comuns em países como Austrália, 
Estados Unidos, Reino Unido, Dinamarca e outras nações da Europa e da costa oriental do Mar Mediterrâneo (ASCE, 1989; FIRER; FRIEDLER; LAHAV, 2008; GANIGUE et al., 2011; HVITVED-JACOBSEN, 2002; JAMEEL, 1989; POULTON et al., 2002). Sais de cloreto, nitrato e sulfato $\left(\mathrm{FeCl}_{3}, \mathrm{FeCl}_{2}, \mathrm{Fe}\left(\mathrm{NO}_{3}\right)_{3}, \mathrm{Fe}_{2}\left(\mathrm{SO}_{4}\right)_{3}\right)$ fornecem duas espécies de ferro dissolvido, os íons férrico $\left(\mathrm{Fe}^{3+}\right)$ e ferroso $\left(\mathrm{Fe}^{2+}\right)$, que atuam de três maneiras diferentes:

1. $\mathrm{o} \mathrm{Fe}^{2+}$ tende a formar uma variedade de precipitados pela reação com os sulfetos dissolvidos, sendo a forma mais comum para descrever a reação apresentada na Equação 8. Contudo, existe a possibilidade de ocorrerem outras reações de precipitação com a formação de pirita $\left(\mathrm{FeS}_{2}\right)$ e outras espécies intermediárias como $\mathrm{Fe}(\mathrm{HS})_{\mathrm{n}}$ (DROBNER et al., 1990; PADIVAL; KIMBELL; REDNER, 1995; WEI \& OSSEO-ASARE, 1995);

2. o $\mathrm{Fe}^{3+}$ oxida os sulfetos dissolvidos a $\mathrm{SO}_{4}^{-}$ou $\mathrm{S}^{0}$ (Equações 9 e 10) e se reduz a $\mathrm{Fe}^{2+}$ (levando a reações de precipitação subsequentes), contudo, da mesma forma que no caso do $\mathrm{Fe}^{2+}$, existe a possibilidade de ocorrerem outras reações com a formação de precipitados como $\mathrm{Fe}_{2} \mathrm{~S}_{3}$ e $\mathrm{Fe}_{3} \mathrm{~S}_{4}$ (DAVYDOV; CHUANG; SANGER, 1998);

3. a utilização de ambas as formas iônicas conduz ao mecanismo da Equação 11 e também às reações já mencionadas (PADIVAL; KIMBELL; REDNER, 1995).

$$
\begin{aligned}
& \mathrm{Fe}^{2+}+\mathrm{HS}^{-} \rightarrow \mathrm{FeS} \downarrow+\mathrm{H}^{+} \\
& 2 \mathrm{Fe}^{3+}+\mathrm{HS}^{-} \rightarrow 2 \mathrm{Fe}^{2+}+\mathrm{S}^{0} \downarrow \\
& 8 \mathrm{Fe}^{3+}+\mathrm{HS}^{-}+4 \mathrm{H}_{2} \mathrm{O} \rightarrow 8 \mathrm{Fe}^{2+}+\mathrm{SO}_{4}^{2-}+9 \mathrm{H}^{+} \\
& \mathrm{Fe}^{2+}+2 \mathrm{Fe}^{3+}+4 \mathrm{HS}^{-} \rightarrow \mathrm{Fe}_{3} \mathrm{~S}_{4} \downarrow+4 \mathrm{H}^{+}
\end{aligned}
$$

Conforme foi apresentado, as reações que ocorrem entre as espécies de ferro e os sulfetos (Ex.: HS ${ }^{-}$) no esgoto ainda não foram completamente elucidadas, e a aplicação da técnica de controle de odores depende fortemente de experiências empíricas, que muitas vezes são específicas para cada caso (FIRER; FRIEDLER; LAHAV, 2008). Corrobora com a afirmativa anterior o fato de, nas condições de ambiente típicas dos esgotos domésticos, a oxidação dos sulfetos dissolvidos a $\mathrm{SO}_{4}{ }^{2-}$ pela ação do $\mathrm{Fe}^{3+}$ ser termodinamicamente favorável (FIRER; FRIEDLER; LAHAV, 2008), mas, na prática, diversos autores reportam a formação de $\mathrm{S}^{0}$ em vez de $\mathrm{SO}_{4}^{2-}$ (LAHAV et al., 2004; PADIVAL; KIMBELL; REDNER, 1995).

Para o controle da geração de odores, a aplicação dos sais de ferro é feita diretamente nas redes coletoras, nas estações elevatórias ou nas linhas de recalque, em doses que podem variar de 0,9 a 5,3 $\mathrm{kgFe}$ por kgS (FIRER; FRIEDLER; LAHAV, 2008; GANIGUE et al., 2011; JAMEEL, 1989; NIELSEN; HVITVED-JACOBSEN; VOLLERTSEN, 2005; PADIVAL; KIMBELL; REDNER, 1995; TOMAR \& ABDULLAH, 1994; VAN DURME \& BERKENPAS, 1989; WERF, 2007), o que leva a reações que duram algumas horas (NIELSEN; HVITVED-JACOBSEN;
VOLLERTSEN, 2005). Não há um consenso sobre a melhor espécie a ser aplicada, $\mathrm{Fe}^{3+}$ ou $\mathrm{Fe}^{2+}$ (ZHANG et al., 2008), mas existem evidências suficientes para se afirmar que a aplicação conjunta das espécies pode levar a uma maior efetividade na remoção dos sulfetos, sendo recomendada a aplicação de $\mathrm{FeSO}_{4}$ e $\mathrm{FeCl}_{3}$ em uma proporção de 1:2 (WERF, 2007). No entanto, quando é necessária a aplicação da técnica em um ponto mais próximo à ETE (Ex.: na linha de recalque), é recomendada a aplicação da espécie $\mathrm{Fe}^{2+}$ devido à sua rápida velocidade de reação (PARK et al., 2014).

Em uma abordagem mais inovadora, Sun et al. (2015) avaliaram a eficiência da aplicação do lodo de decantadores de estações de tratamento de água que utilizam sais de ferro na etapa de coagulação/floculação para o controle de odores nos terminais de linhas de recalque de esgoto bruto, obtendo eficiências da ordem de $90 \%$ na remoção dos sulfetos dissolvidos.

Uma observação interessante é que, quando aplicados nos sistemas de coleta de esgoto, a montante de estações que utilizam processos aeróbios de tratamento, os sais de ferro podem favorecer a remoção de fósforo pela formação de complexo de fosfatos férricos (aprox. 0,4 kgP- $\mathrm{PO}_{4}^{3-}$ a cada kgFe adicionado) (GUTIERREZ et al., 2010). Contudo, os precipitados formados nas reações podem aumentar substancialmente a produção de lodo no sistema de tratamento.

\section{Elevação de $\mathrm{pH}$}

Além de ser um parâmetro interveniente importante na maioria dos métodos de controle de odores descritos anteriormente, o pH também pode ser usado diretamente para prevenir a liberação de $\mathrm{H}_{2} \mathrm{~S}_{(\mathrm{g})}$ em sistemas de coleta e tratamento de esgoto. Existem dois métodos utilizados no controle da emanação de odores pelo aumento do pH (WERF, 2007):

1. alteração do $\mathrm{pH}$ para favorecer a ionização do $\mathrm{H}_{2} \mathrm{~S}_{(\mathrm{aq})}$ (formando HS- e, principalmente, $\mathrm{S}^{2-}$ );

2. controle da formação dos sulfetos pela ação biocida do $\mathrm{pH}$ muito elevado.

O hidróxido de magnésio $\left(\mathrm{Mg}(\mathrm{OH})_{2}\right)$ e o hidróxido de sódio $(\mathrm{NaOH})$ são os dois produtos químicos mais comumente usados para elevar o $\mathrm{pH}$. Devido à sua baixa solubilidade, $\mathrm{o} \mathrm{Mg}(\mathrm{OH})_{2}$ pode elevar o $\mathrm{pH}$ até 9,0, enquanto que o $\mathrm{NaOH}$ pode elevar o $\mathrm{pH}$ até 14,0 (MOORE, 2003; WERF, 2007). A cal $\left(\mathrm{Ca}(\mathrm{OH})_{2}\right)$ também pode ser usada, mas é bastante insolúvel e pode provocar problemas de incrustações (USEPA, 1985).

As dosagens de $\mathrm{Mg}(\mathrm{OH})_{2}$ e $\mathrm{NaOH}$ reportadas na literatura variam muito em função das características dos esgotos e das diferentes contribuições de correntes de esgoto nas redes de coleta e nas ETEs. Dessa forma, é recomendável a realização de ensaios de laboratório com amostras reais de esgoto para a determinação das doses necessárias para se atingir um determinado $\mathrm{pH}$, a exemplo de titulações ou jar-testes. Contudo, na aplicação da dosagem determinada em laboratório 
em escala real, deve-se considerar a possibilidade de diluição da fase líquida a partir dos fluxos de esgoto a jusante, o que certamente pode levar a uma redução do $\mathrm{pH}$. Como parâmetro de referência, para a alteração do $\mathrm{pH}$ no intuito de favorecer a ionização do $\mathrm{H}_{2} \mathrm{~S}_{(\mathrm{aq})}$ em um interceptor de esgoto, WERF (2007) reporta a aplicação de cerca de $80 \mathrm{gMg}(\mathrm{OH})_{2} \cdot \mathrm{m}^{-3}$ de esgoto para a obtenção de uma eficiência de $80 \%$ na redução do $\mathrm{H}_{2} \mathrm{~S}_{(\mathrm{g})}$ existente na atmosfera de um interceptor. WERF (2007) reporta ainda a redução de 70 a $80 \%$ da concentração de $\mathrm{H}_{2} \mathrm{~S}_{(\mathrm{g})}$ em uma rede de coleta de esgoto com a aplicação de $90 \mathrm{gNaOH} \cdot \mathrm{m}^{-3}$ de esgoto em pontos estratégicos da rede. Já aplicação de $\mathrm{NaOH}$ como biocida ou na inativação das BRS deve ser feita de modo a garantir que o $\mathrm{pH}$ no ponto crítico de emanação de odores permaneça acima de 10,5 por algumas horas, o que deverá garantir uma certa inativação das bactérias por um período de uma a duas semanas. Como parâmetro de referência, Gutierrez et al. (2014) dosaram 520 gNaOH.m ${ }^{-3}$ de esgoto no início de uma linha de recalque de esgoto bruto por cerca de $6 \mathrm{~h}$, elevando o $\mathrm{pH}$ no ponto de aplicação para 11,5 e, na saída da linha de recalque, para 10,5 durante 4 horas. Esse efeito foi suficiente para garantir uma redução de $67 \%$ na concentração dos sulfetos dissolvidos durante uma semana.

\section{Análise comparativa das técnicas de adição de produtos químicos ou aeração}

Na Tabela 1, são relacionadas as principais técnicas utilizadas para a minimização da geração de odores em sistemas de coleta e tratamento de esgoto (discutidas nas seções anteriores), assim como as vantagens/ desvantagens e dosagens de produtos químicos aplicadas em cada uma (BENTZEN et al., 1995; EINARSEN et al., 2000; FIRER; FRIEDLER; LAHAV, 2008; GANIGUE et al., 2011; GARCIA DE LOMAS et al., 2006; GUTIERREZ et al., 2008; 2010; 2014; HOBSON \& YANG, 2000; JAMEEL, 1989; MOODY \& RIEK, 1999 apud ZHANG et al., 2008; NIELSEN; HVITVED-JACOBSEN; VOLLERTSEN, 2005; PADIVAL; KIMBELL; REDNER, 1995; PARK et al., 2014; RODRIGUEZ-GOMEZ et al., 2005; TOMAR \& ABDULLAH, 1994; USEPA, 1985; 1991; VAN DURME \& BERKENPAS, 1989; WALTRIP \& SNYDER, 1985; WEF, 2004; YANG; VOLLERTSEN; HVITVED-JACOBSEN, 2005; ZHANG et al., 2008).

\section{MEDIDAS CORRETIVAS: CONTENÇÃO, EXAUSTÃO E TRATAMENTO DE GASES ODORANTES}

Em uma ETE, pode ser indispensável o tratamento dos gases odorantes inevitavelmente emitidos, mesmo depois de aplicadas as medidas preventivas descritas anteriormente, sendo, para isso, necessária a cobertura/contenção das fontes problemáticas de emissão, a exaustão dos gases e, por fim, o tratamento e/ou dispersão.

\section{Tipos de coberturas}

A seguir serão detalhados alguns tipos de coberturas mais empregados em ETEs.

Coberturas planas: são comumente aplicadas em canais, caixas de distribuição, poços, tanques, dentre outras unidades em uma ETE (Figuras 1A e 1B). No emprego desse tipo de cobertura, deve-se avaliar se a espessura necessária para vencer os esforços de flexão não é demasiadamente elevada, o que levaria a escolha de outro tipo de cobertura com menor espessura (Ex.: uso de coberturas em arco, conforme abordado a seguir). Dependendo da aplicação, pode ser necessária a instalação de suporte estrutural interno ou externo. Caso se opte pelo suporte interno, deve ser prevista a proteção da estrutura contra a corrosão, uma vez que a atmosfera no interior da cobertura estará relativamente concentrada de $\mathrm{H}_{2} \mathrm{~S}$ e umidade. As coberturas planas não proporcionam acesso do operador à unidade coberta ou permitem apenas o acesso limitado por meio de comportas, janelas ou módulos deslizantes. Dificultam a habilidade do operador em antecipar e reagir às mudanças na qualidade e na vazão do esgoto, mas, por outro lado, também restringem o acesso a zonas que ofereçam riscos à saúde e à segurança do trabalhador. Minimizam o volume de ar enclausurado entre o nível d'água e a cobertura e, consequentemente, os custos dos sistemas de exaustão e tratamento dos gases. Ademais, como são coberturas não visitáveis ou com acesso limitado, permite-se a aplicação de menores taxas de renovação de ar, variando entre 4 e 6 renovações/hora (WEF, 2004). Existem algumas situações em que certas seções de uma unidade do processo podem emitir consideravelmente mais odores e, nesses casos, o uso de coberturas planas diretamente sobre a fonte de emissão pode reduzir consideravelmente os odores, sem que haja a cobertura total da unidade de tratamento (Figura 1C).

Coberturas em arco: são utilizadas para a contenção de odores em canais e tanques que possuem grandes vãos, suficientes para impedir o emprego de coberturas planas sem suporte de sustentação (Figura 1D). Como as coberturas planas, também proporcionam acesso limitado do operador. Causam maior impacto estético e o volume de ar enclausurado será maior, o que pode levar a um aumento dos custos de exaustão e tratamento dos gases. Experiências em escala real demonstram a necessidade de uso de maiores taxas de renovação de ar em coberturas em arco, sendo satisfatória a aplicação de 6 renovações/hora (WEF, 2004).

Coberturas do tipo telhado de duas águas: possuem as mesmas características das coberturas em arco em termos de aplicabilidade, vantagens e desvantagens. As coberturas em telhado de duas águas possuem uma desvantagem adicional, sendo necessário, dependendo do tamanho do vão a ser vencido, o uso de suportes adicionais nas placas da cobertura. Esses suportes podem reduzir a visibilidade e o acesso do operador ainda mais. 
Tabela 1 - Análise comparativa das principais técnicas utilizadas para a minimização de emissões odorantes em redes e ETEs.

\begin{tabular}{|c|c|c|c|c|}
\hline Técnicas & $\begin{array}{l}\text { Produtos } \\
\text { químicos }\end{array}$ & Vantagens & Desvantagens & $\begin{array}{l}\text { Doses } \\
\text { aplicadas }\end{array}$ \\
\hline $\begin{array}{l}\text { Aeração ou } \\
\text { oxigenaç̧ão }\end{array}$ & $\mathrm{O}_{2}$ & $\begin{array}{l}\text { - Menores custos em relação às demais técnicas; } \\
\text { - Não introduz substâncias no esgoto que podem } \\
\text { comprometer o tratamento biológico a jusante (no } \\
\text { caso de ETEs com reatores aeróbios); } \\
\text { - Simplicidade operacional; } \\
\text { - Remoção incremental de matéria orgânica antes da ETE. }\end{array}$ & $\begin{array}{l}\text { - Quando aplicada em condutos livres, pode } \\
\text { ser dispendiosa devido à limitada taxa de } \\
\text { transferência de oxigênio; } \\
\text { - No caso de ETEs com reatores anaeróbios, } \\
\text { a aplicação a montante do tratamento pode } \\
\text { induzir condições aeróbias indesejáveis ao } \\
\text { tratamento ou, em uma melhor condição, } \\
\text { induzir condições microaeróbias no interior } \\
\text { dos reatores. }\end{array}$ & $\begin{array}{c}0,2-6,6 \\
m^{3} \text { ar.m-3 }{ }^{-3} \text { sgoto }\end{array}$ \\
\hline \multirow{3}{*}{$\begin{array}{l}\text { Adição de } \\
\text { oxidantes } \\
\text { fortes }\end{array}$} & $\mathrm{H}_{2} \mathrm{O}_{2}$ & $\begin{array}{l}\text { - Além de oxidar os sulfetos, } \mathrm{O}_{2} \mathrm{O}_{2} \text { se decompõe em } \\
\mathrm{H}_{2} \mathrm{O} \text { e } \mathrm{O}_{2} \text {, fornecendo condições para a formação de } \\
\text { ambientes aeróbios; } \\
\text { - Remoção incremental de matéria orgânica antes da ETE. }\end{array}$ & $\begin{array}{l}\text { - Manuseio/armazenamento do } \mathrm{H}_{2} \mathrm{O}_{2} \text { demanda } \\
\text { procedimentos de segurança especificos; } \\
\text { - Não reage somente com os sulfetos } \\
\text { dissolvidos e é prontamente consumido por } \\
\text { meio de outras reações (uso de doses em } \\
\text { excesso); } \\
\text { - Baixa velocidade de reação em relação a } \\
\text { outras técnicas; } \\
\text { - Difícil manutenção de concentrações } \\
\text { residuais de } \mathrm{H}_{2} \mathrm{O}_{2} \text {. }\end{array}$ & $\begin{array}{c}1,3-4, \mathrm{O} \\
\mathrm{gH}_{2} \mathrm{O}_{2} \cdot(\mathrm{gS})^{-1}\end{array}$ \\
\hline & $\begin{array}{c}\mathrm{Cl}_{2} \\
\mathrm{NaClO}\end{array}$ & $\begin{array}{l}\text { - Longo histórico de eficácia; } \\
\text { - Estrutura necessária para manuseio/armazenamento } \\
\text { amplamente disponível no mercado. }\end{array}$ & $\begin{array}{l}\text { - Reage formando subprodutos organoclorados } \\
\text { prejudiciais; } \\
\text { - Não reage somente com os sulfetos } \\
\text { dissolvidos e é prontamente consumido } \\
\text { pela amônia (uso de doses em excesso); } \\
\text { - Pode inibir o tratamento biológico a jusante; } \\
\text { - Manuseio/armazenamento do } \mathrm{Cl}_{2} \text { demanda } \\
\text { procedimentos de segurança específicos; } \\
\text { - Injeção direta de } \mathrm{Cl}_{2} \text { pode causar problemas a } \\
\text { jusante pela liberação de gás cloro potencial- } \\
\text { mente perigoso; } \\
\text { - Difícil manutenção de concentrações } \\
\text { residuais de cloro. }\end{array}$ & $\begin{array}{c}4,0-15,0 \\
\mathrm{gCl}_{2} \cdot(\mathrm{gS})^{-1} \\
2, \mathrm{O}^{-1}-15, \mathrm{O} \\
\mathrm{gNaOCl} \cdot(\mathrm{gS})^{-1}\end{array}$ \\
\hline & $\begin{array}{c}\mathrm{KMnO}_{4} \\
\mathrm{NaMnO}_{4}\end{array}$ & $\begin{array}{l}\text { - Reação com os sulfetos forma } \mathrm{MnO}_{2} \text {, que contribui } \\
\text { para a floculação de sólidos suspensos no tratamento; } \\
\text { - Reage preferencialmente com os sulfetos (mais aplicável } \\
\text { para o tratamento de lodo, em função da elevada } \\
\text { concentração de matéria orgânica); } \\
\text { - Quando utilizados para o tratamento de lodo, a unidade } \\
\text { de desidratação poderá atingir maiores eficiências. }\end{array}$ & $\begin{array}{l}\text { - Maiores custos em relação às demais } \\
\text { técnicas (geralmente só possui viabilidade } \\
\text { econômica para o tratamento de lodo); } \\
\text { - Difícil manutenção de concentrações. } \\
\text { residuais de } \mathrm{MnO}_{4} \text {. }\end{array}$ & $\begin{array}{c}6-7 \\
\mathrm{gKMnO}_{4} \cdot(\mathrm{gS})^{-1} \\
7-8 \\
\mathrm{gNaMnO}_{4} \cdot(\mathrm{gS})^{-1}\end{array}$ \\
\hline $\begin{array}{l}\text { Adição } \\
\text { de sais de } \\
\text { ferro }\end{array}$ & $\begin{array}{l}\mathrm{FeCl} \\
\mathrm{Fe}(\mathrm{Cl})_{2} \\
\mathrm{Fe}\left(\mathrm{NO}_{3}\right)_{3} \\
\mathrm{Fe}_{2}\left(\mathrm{SO}_{4}\right)_{3}\end{array}$ & $\begin{array}{l}\text { - Boa manutenção de concentrações residuais dos sais; } \\
\text { - Podem ser aplicados diretamente em lodo de ETEs; } \\
\text { - Manuseio/armazenamento dos sais é simples e seguro } \\
\text { e eles não reagem formando subprodutos perigosos; } \\
\text { - Os precipitados formados podem ser benéficos para } \\
\text { os processos de decantação utilizados no tratamento } \\
\text { a jusante; } \\
\text { - Quando aplicados a montante de sistemas aeróbios } \\
\text { de tratamento podem favorecer a remoção de fósforo; } \\
\text { - Reagem seletivamente com os sulfetos. }\end{array}$ & $\begin{array}{l}\text { - Os precipitados podem dissociar em } \\
\text { pH inferior a 6,5, levando novamente à } \\
\text { formação de sulfetos dissolvidos; } \\
\text { - Podem gerar incrustações quando } \\
\text { aplicados em redes coletoras ou em } \\
\text { efluentes de reatores anaeróbios; } \\
\text { - Podem aumentar substancialmente } \\
\text { a produção de lodo no sistema de } \\
\text { tratamento. }\end{array}$ & $\begin{array}{l}1,2-5,3 \\
\text { gFe.(gS) }\end{array}$ \\
\hline $\begin{array}{l}\text { Elevação } \\
\text { do pH }\end{array}$ & $\begin{array}{c}\mathrm{Mg}(\mathrm{OH})_{2} \\
\mathrm{NaOH}\end{array}$ & $\begin{array}{l}\text { - O manuseio/armazenamento das bases é simples e } \\
\text { seguro; } \\
\text { - Pode ser aplicado de modo intermitente (uma vez por } \\
\text { semana), desde que os compostos químicos sejam } \\
\text { dosados em altas concentrações em um curto intervalo } \\
\text { de tempo (elevações súbitas e grandes de pH). }\end{array}$ & $\begin{array}{l}\text { - Possui efeito temporário. A mistura ou diluição } \\
\text { do esgoto a jusante do ponto de aplicação } \\
\text { pode levar às condições de desprendimento } \\
\text { de } \mathrm{H}_{2} \mathrm{~S} \text { (pela diminuição do pH); } \\
\text { - Pode inibir o tratamento biológico a jusante. }\end{array}$ & $\begin{array}{l}\sim 8 \mathrm{OgMg}(\mathrm{OH})_{2} \mathrm{~m}^{-3} \\
\sim 9 \mathrm{OgNaOH} \mathrm{m}^{-3} \\
>5 \mathrm{OOgNaOH} \mathrm{m}^{-3} \\
\text { para elevações } \\
\text { súbitas de pH }\end{array}$ \\
\hline
\end{tabular}

Fonte: adaptado de WERF (2007). 
Galpão ou cúpula: permite a ocupação do espaço enclausurado e o acesso irrestrito dos operadores (Ex.: galpão utilizado para cobrir uma determinada área da ETE, cúpula utilizada para cobrir um decantador ou um tanque circular etc.). Nesse tipo de configuração, a exaustão dos gases deve ser feita o mais próximo possível da fonte geradora de odor. Considerando o baixo coeficiente de difusão do $\mathrm{H}_{2} \mathrm{~S}$, as aberturas para insuflamento de ar atmosférico devem ser alocadas na parte superior do galpão, de forma a garantir a exposição dos operadores ao ar fresco e evitar a exposição aos gases odorantes (Figura 1E). Por serem coberturas visitáveis, normalmente são empregadas taxas de renovação de ar superiores, na ordem de 12 renovações/hora (WEF, 2004). Além disso, essas coberturas possuem um volume de enclausuramento maior e, portanto, geram maiores vazões de ar para tratamento. Deve-se atentar para as questões de saúde e segurança do trabalhador. Os operadores devem ser treinados a entrarem em ambientes confinados e devem possuir sensores de monitoramento das concentrações de $\mathrm{H}_{2} \mathrm{~S}$ no ar, sendo estabelecido um limite de tolerância de 8 ppm para jornadas de trabalho de até 48 h por semana - NR 15 do Ministério do Trabalho e Emprego (BRASIL, 1978).

\section{Sistemas de exaustão}

Os sistemas de exaustão podem ser compostos por áreas não visitáveis (inacessíveis ao operador ou que possuem acesso limitado), áreas visitáveis (com acesso irrestrito do operador) dutos e exaustores. A seguir, são apresentados os principais elementos necessários ao dimensionamento de cada componente.

Áreas não visitáveis: a exaustão faz-se necessária nesses tipos de ambiente para purgar os gases enclausurados relativamente concentrados de umidade, $\mathrm{H}_{2} \mathrm{~S}$ e outros compostos sulfurosos, que podem levar à corrosão da cobertura e das estruturas de concreto e aço. O cálculo da vazão de exaustão dos gases em áreas não visitáveis é função de três fatores, sendo adotado o maior valor obtido entre os três (WERF, 2007):

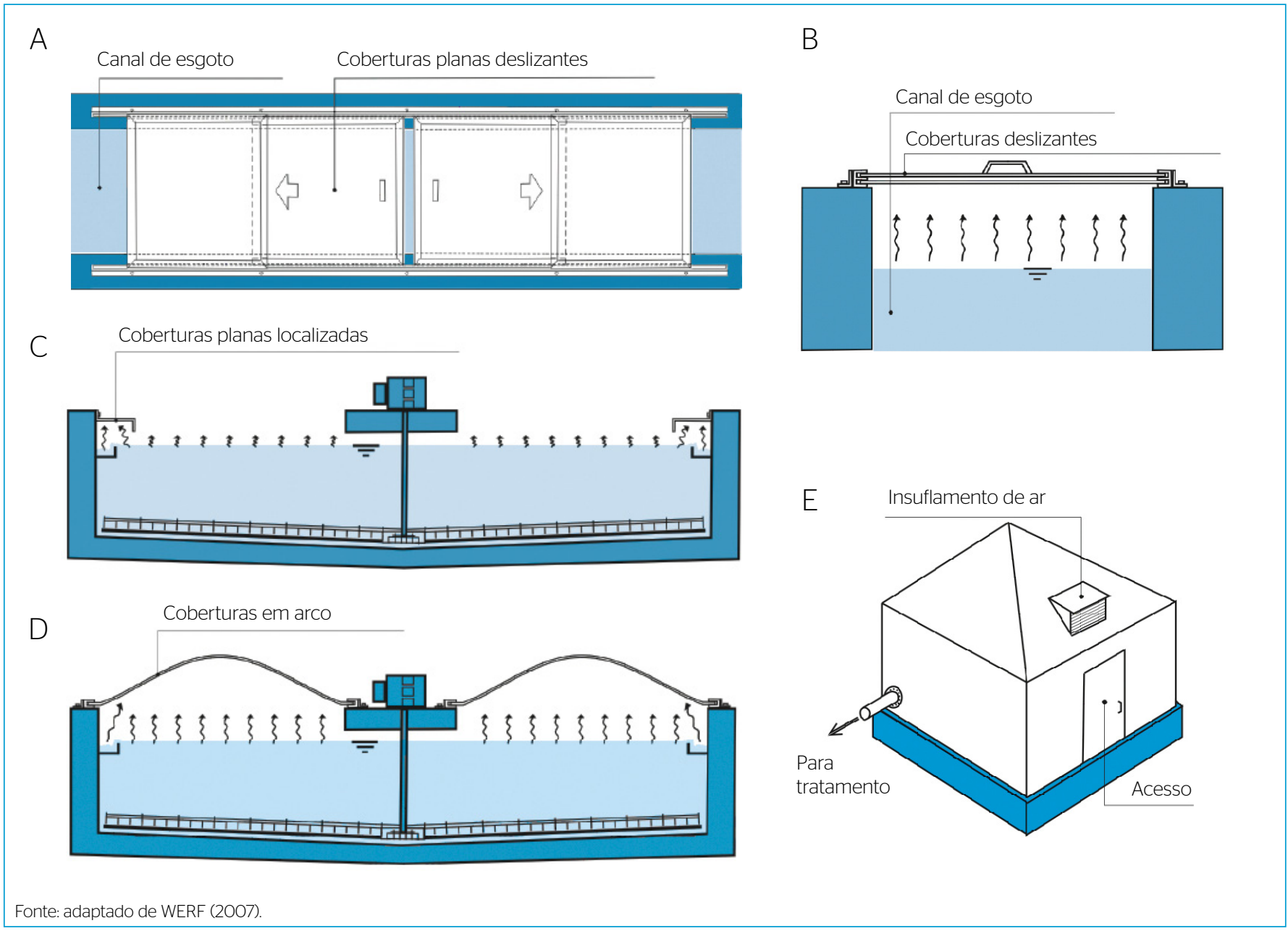

Figura 1 - Representação dos principais tipos de coberturas utilizadas para a contenção e a exaustão de gases odorantes em ETEs. (a) coberturas planas com articulação para proporcionar acesso ao local confinado; (b) corte de um canal com coberturas planas; (d) coberturas em arco ou do tipo telhado de duas águas; (e) galpão ou cúpula. 
1. taxa de renovação da atmosfera. Valores mínimos necessários para impedir o acúmulo de umidade na cobertura e nas estruturas internas são de 3 a 4 renovações/h, sendo recomendados valores de 4 a 6 renovações/h para o controle de odores;

2. pressão diferencial. Para que os gases confinados na cobertura não escapem para a atmosfera exterior, deve-se manter uma pressão diferencial negativa de 2,5 mmCA entre o volume confinado e a atmosfera exterior, determinada pela velocidade nominal do gás nas aberturas de insuflamento da cobertura, normalmente $6,4 \mathrm{~m} . \mathrm{s}^{-1}$

3. concentração de $\mathrm{H}_{2} \mathrm{~S}$. Alguns tipos de sistemas de tratamento de gases odorantes demandam faixas de concentrações típicas dos contaminantes no gás afluente, sendo necessária a diluição do gás para a adequação das concentrações.

Áreas visitáveis: a exaustão dos gases odorantes é necessária primeiramente para se garantir a saúde e segurança do trabalhador. Nessas áreas é fortemente recomendável o insuflamento forçado de ar atmosférico em conjunto com um sistema de exaustão, que deve ter uma vazão ajustada para não exceder em 10\% a vazão de ar insuflada, de forma a garantir uma pressão negativa adequada no interior da área enclausurada (WERF, 2007). O cálculo da vazão de exaustão dos gases em áreas visitáveis também é função dos três fatores mencionados para o caso das áreas não visitáveis. Contudo, em coberturas visitáveis, é comum o uso de uma taxa de renovação da atmosfera igual a 12 renovações/h (WERF, 2007). Deve-se atentar para as concentrações de $\mathrm{H}_{2} \mathrm{~S}$ no ambiente confinado, de forma a promover uma diluição do gás suficiente para manter as concentrações inferiores a 8 ppm, conforme limite de tolerância para jornadas de trabalho de até $48 \mathrm{~h}$ por semana estabelecido pelo Ministério do Trabalho e Emprego (BRASIL, 1978).

Dutos e exaustores: os dutos usados para a exaustão dos gases confinados podem ser de seção circular ou retangular, a depender do material construtivo. A velocidade do gás nos dutos de coleta e exaustão deve ser definida entre 10 e $15 \mathrm{~m} . \mathrm{s}^{-1}$ (WEF, 2004), sendo admitidos maiores valores, porém, que provocam grandes perdas de carga e demandam exaustores com maior potência. Os dutos de exaustão devem ser inclinados para possibilitar o encaminhamento da umidade condensada para os pontos baixos da rede de exaustão, onde devem ser previstos dispositivos para purga do condensado. Além disso, nos pontos de captação e nas ramificações da rede de dutos, devem ser instalados reguladores para permitir ajustes de vazão e pressão (dampers). Com relação aos exaustores, são recomendados os equipamentos centrífugos ou com pás radiais para fins industriais, fabricados com materiais que resistam à corrosão (solução de ácido sulfúrico $10 \%$ p/v), preferencialmente dotados de pás inclinadas para trás (WEF, 2004). Os exaustores devem ser providos de sistema de drenagem para prevenir o acúmulo do líquido condensado no interior do equipamento.

\section{Tratamento de gases odorantes}

Diferentes tecnologias podem ser utilizadas para o tratamento de gases odorantes gerados em sistemas de coleta e tratamento de esgoto (GARCIA DE LOMAS et al., 2006): métodos físicos, químicos e biológicos (Figura 2). Chernicharo et al. (2010) realizaram uma análise comparativa das tecnologias disponíveis, apresentado as suas características, vantagens e desvantagens. Os autores também ranquearam as tecnologias de acordo com as faixas usuais de concentração e vazão de gases odorantes comumente observadas em ETEs, bem como os aspectos considerados importantes e críticos no Brasil. Os aspectos econômicos (custos de implantação, operação, manutenção e requisitos de energia e de produtos químicos) são amplamente favoráveis aos métodos de combustão direta e aos biofiltros ou biopercoladores (CHERNICHARO et al., 2010). O único aspecto econômico desfavorável aos biofiltros é o requisito de área. Todavia, tal aspecto só é importante na seleção de alternativas quando houver enorme restrição de área em uma ETE. Contrariamente, os aspectos econômicos relativos a custos de operação e manutenção, notadamente aqueles relacionados ao consumo de produtos químicos, são substancialmente desfavoráveis aos métodos de adsorção com carvão ativado e lavadores químicos, apesar de também serem aplicáveis ao tratamento de gases odorantes gerados em ETEs (USEPA, 1985). Alguns parâmetros de projeto e operação de combustores, biofiltros e biopercoladores podem ser obtidos em (CHERNICHARO et al., 2014; KENNES \& VEIGA, 2001; WEF, 2004), enquanto mais detalhes a respeito dos processos de adsorção e dos lavadores químicos podem ser obtidos em Kohl \& Nielsen (1997).

\section{CONSIDERAÇÕES FINAIS}

A corrosão dos sistemas de coleta e tratamento de esgoto e os incômodos provocados nas suas vizinhanças pela emanação de odores são desafios hoje fatalmente enfrentados por empreendimentos do setor de saneamento. A literatura e a experiência técnica mostram que o controle das concentrações dos sulfetos - seja em suas formas dissolvida livre como $\mathrm{H}_{2} \mathrm{~S}_{(\mathrm{aq})}$, ou ionizada, HS e $\mathrm{S}^{2-}$ - nas redes coletoras, estações elevatórias e linhas de recalque de esgoto bruto é fator-chave para a minimização da corrosão e emissão de odores nas etapas posteriores de tratamento, quebrando paradigmas que envolvem a funcionalidade de sistemas de coleta e transporte de esgoto. Além do controle das concentrações de sulfeto de hidrogênio na fase líquida (esgoto bruto), outras técnicas vêm sendo aplicadas com sucesso para a contenção, exaustão e tratamento do sulfeto na sua forma gasosa $-\mathrm{H}_{2} \mathrm{~S}_{(\mathrm{g})}$, após o seu desprendimento da fase líquida. Contudo, o enclausuramento e o tratamento do $\mathrm{H}_{2} \mathrm{~S}_{(\mathrm{g})}$ é uma medida corretiva mitigadora que deve ser aplicada somente quando as medidas preventivas de minimização da geração do $\mathrm{H}_{2} \mathrm{~S}_{(\text {aq) }}$ na fase líquida não forem suficientes ou quando se mostrarem inviáveis para um determinado tipo sistema, como é o caso de ETEs que empregam reatores anaeróbios, nas 


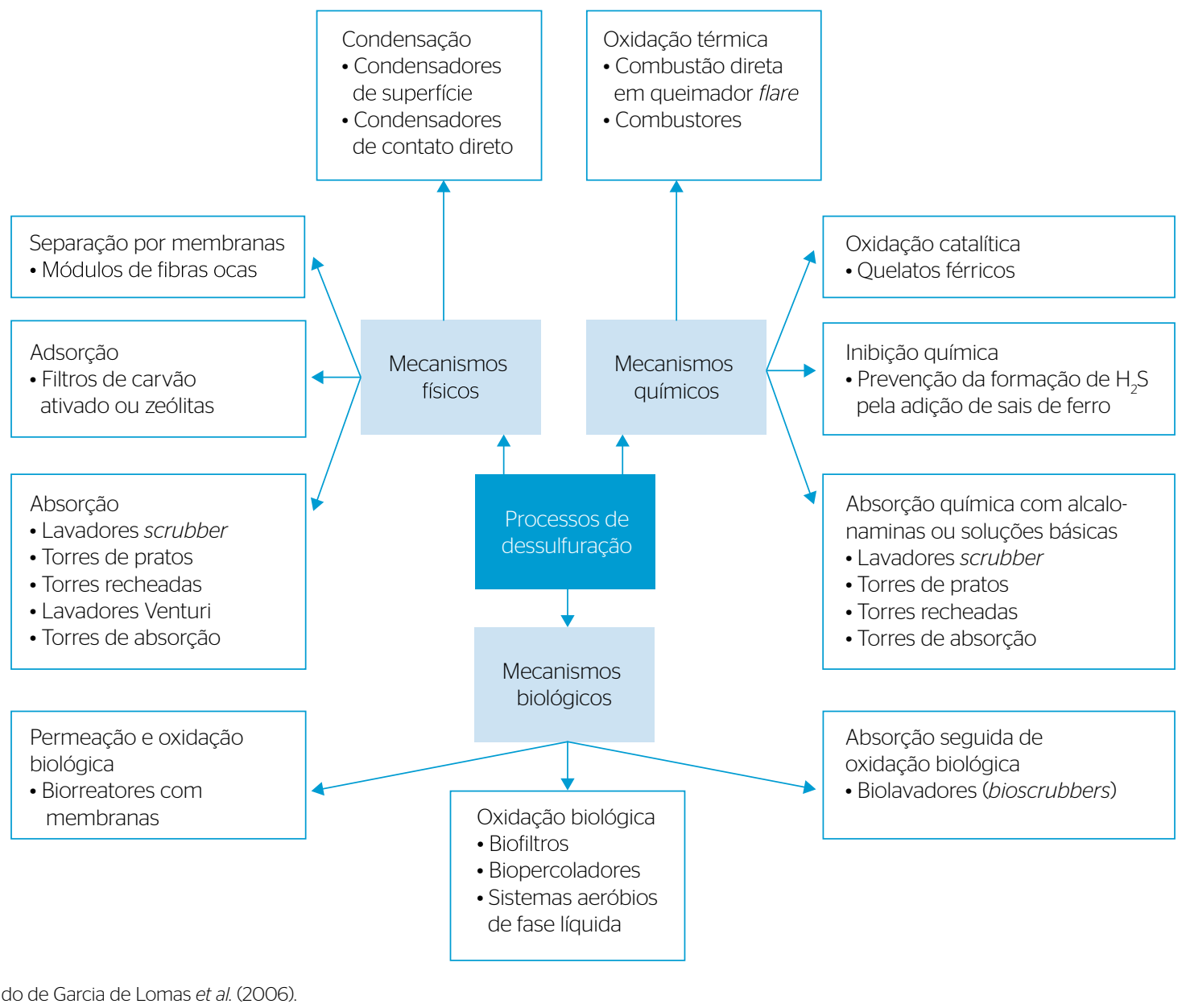

Fonte: adaptado de Garcia de Lomas et al. (2006).

Figura 2 - Rotas tecnológicas para dessulfuração de correntes gasosas.

quais algumas dessas técnicas de minimização encontram pouca aplicabilidade e outras alternativas vêm sendo buscadas (GLÓRIA et al., 2014). Considerando as faixas usuais de concentração e vazão de gases odorantes comumente observadas em ETEs bem como os aspectos considerados importantes e críticos no Brasil, dentre as tecnologias atualmente disponíveis ou em desenvolvimento no meio técnico/científico para o tratamento de correntes gasosas contendo $\mathrm{H}_{2} \mathrm{~S}$, destacam-se os métodos de combustão direta, os biofiltros, os biopercoladores, em detrimento de métodos de adsorção e dos lavadores químicos. Mas ressalta-se que a decisão sobre qual alternativa adotar deverá resultar de um balanço entre critérios técnicos, econômicos e ambientais, levando-se em consideração os aspectos apresentados neste artigo em outras referências apontadas.

\section{REFERÊNCIAS}

AL-SHAMMIRI, M. (2004) Hydrogen sulfide emission from the Ardiyah sewage treatment plant in Kuwait. Desalination, v. 170, n. 1, p. 1-13.

ASCE - American Society of Civil Engineers. (1989) Sulfide in wastewater collection and treatment systems: manuals and reports on engineering practice. 69. ed. Reston: American Society of Civil Engineers. 338p.
ASCE - American Society of Civil Engineers. (1995) Manuals and reports on engineering practice. 82. ed. New York: American Society of Civil Engineers.

AUGUET, O.; PIJUAN, M.; GUASCH-BALCELLS, H.; BORREGO, C.M.; GUTIERREZ, O. (2O15) Implications of downstream nitrate dosage in anaerobic sewers to control sulfide and methane emissions. Water Research, v. 68, p. 522-532. 
AZEVEDO, A.D.P.; ELIAS, V.F.; MORAES, I.P.S.; PELICER, A.I.; SILVA, N.L. (1993) Redução do odor através da aplicação de nitrato de amônio. In: Congresso Brasileiro de Engenharia Sanitária e Ambiental, 17., Natal. Anais... Natal: ABES. p. 693-704.

BENTZEN, G.; SMITH, A.T.; BENNET, D.; WEBSTER, N.J.; REINHOLT, F.; SLETHOLT, E.; HOBSON, J. (1995) Controlled dosing of nitrate for prevention of $\mathrm{H} 2 \mathrm{~S}$ in a sewer network and the effects on the subsequent treatment process. Water Science and Technology, v. 31, p. 293-302.

BOHN, H.L. (1993) Bioprocessing of organic gases in waste air. In: Symposium on Bioremediation and Bioprocessing, 205. Anais... Denver: American Chemical Society. p. 287-289.

BOON, A.G.; VINCENT, A.J.; BOON, K.G. (1998) Avoiding the problems of septic sewage. Water Science and Technology, v. 37 , n. 1, p. 223-231.

BRASIL. (1978) Normas regulamentadoras: NR-15 - atividades e operações insalubres. Diário Oficial da União.

CHEN, G.H. \& LEUNG, D.H.W. (2000) Utilization of oxygen in a sanitary gravity sewer. Water Research, v. 34, n. 15, p. 3813-3821.

CHERNICHARO, C.A.L.; STUETZ, R.M.; SOUZA, C.L.; MELO, G.C.B. (2010) Alternativas para o controle de emissões odorantes em reatores anaeróbios tratando esgoto doméstico. Engenharia Sanitária e Ambiental, v. 15, n. 3, p. 229-236.

CHERNICHARO, C.A.L.; STUETZ, R.M.; SOUZA, C.L.; MELO, G.C.B. (2014) Contribuição para o projeto de biofiltros aplicados ao tratamento de emissões odorantes provenientes de reatores anaeróbios. Revista DAE, n. 186, p. 56-62.

CHURCHILL, P. \& ELMER, D. (1999) Hydrogen sulfide odor control in wastewater collection systems. Journal of New England Water Environment Association, v. 33, n. 1, p. 57.

DAVYDOV, A.; CHUANG, K.T.; SANGER, A.R. (1998) Mechanism of $\mathrm{H}_{2} \mathrm{~S}$ oxidation by ferric oxide and hydroxide surfaces. The Journal of Physical Chemistry B, v. 102, n. 24, p. 4745-4752.

DE HEYDER, B. \& THOEYE, C. (2000) A conscious scheme for remediation of odour nuisance at sewage treatment plants. Water Science and Technology, v. 41, n. 6, p. 9-16.

DELGADO, S.; ALVAREZ, M.; AGUIAR, E.; RODRÍGUEZ-GÓMEZ, L.E. (1998) Effect of dissolved oxygen in reclaimed wastewater transformation during transportation. Case study: Tenerife, Spain. Water Science and Technology, v. 37, n. 1, p. 123-130.

DELGADO, S.; ALVAREZ, M.; RODRIGUEZ-GOMEZ, L.; ELMALEH, S. (2004) Transportation of reclaimed wastewater through a long pipe: inhibition of sulphide production by nitrite from the secondary treatment. Environmental Technology, v. 25, n. 3, p. 365-371.

DROBNER, E.; HUBER, H.; WACHTERSHAUSER, G.; ROSE, D.; STETTER, K. (1990) Pyrite formation linked with hydrogen evolution under anaerobic conditions. Nature, v. 346, p. $742-744$
EINARSEN, A.M.; AESOY, A.; RASMUSSEN, A.I.; BUNGUM, S.; SVEBERG, M. (2000) Biological prevention and removal of hydrogen sulphide in sludge at Lillehammer wastewater treatment plant. Water Science and Technology, v. 41, n. 6, p. 175-187.

FIRER, D.; FRIEDLER, E.; LAHAV, O. (2008) Control of sulfide in sewer systems by dosage of iron salts: comparison between theoretical and experimental results, and practical implications. Science of the Total Environment, v. 392, n. 1, p. 145-156

GANIGUE, R.; GUTIERREZ, O.; ROOTSEY, R.; YUAN, Z. (2O11) Chemical dosing for sulfide control in Australia: an industry survey. Water Research, v. 45, n. 19, p. 6564-6574.

GARCIA DE LOMAS, J.; CORZO, A.; GONZALEZ, J.M.; ANDRADES, J.A.; IGLESIAS, E.; MONTERO, M.J. (2006) Nitrate promotes biological oxidation of sulfide in wastewater: experiment at plant-scale. Biotechnology and Bioengineering, v. 93, n. 4, p. 801-811.

GLÓRIA, R.M.; MOTTA, T.M.; SILVA, P.V.O.; COSTA, P.; SOUZA, C.L.; CHERNICHARO, C.A.L. (2014) Stripping and dissipation techniques for the removal of dissolved gases from anaerobic effluents. In: Latin American Workshop and Symposium on Anaerobic Digestion, 11. Anais... Havana: IWA.

GUTIERREZ, O.; MOHANAKRISHNAN, J.; SHARMA, K.R.; MEYER, R.L.; KELLER, J.; YUAN, Z. (2008) Evaluation of oxygen injection as a means of controlling sulfide production in a sewer system. Water Research, v. 42, n. 17, p. 4549-4561.

GUTIERREZ, O.; PARK, D.; SHARMA, K.R.; YUAN, Z. (2010) Iron salts dosage for sulfide control in sewers induces chemical phosphorus removal during wastewater treatment. Water Research, v. 44, n. 11, p. $3467-3475$

GUTIERREZ, O.; SUDARJANTO, G.; REN, G.; GANIGUÉ, R.; JIANG, G.; YUAN, Z. (2014) Assessment of pH shock as a method for controlling sulfide and methane formation in pressure main sewer systems. Water Research, v. 48, p. 569-578.

HOBSON, J. \& YANG, G. (2000) The ability of selected chemicals for suppressing odour development in rising mains. Water Science and Technology, v. 41, n. 6, p. 165-173.

HOLDER, G.A. \& LEOW, J.M. (1994) In-sewer oxygenation of wastewater using venturi side-stream dissolvers. Water Science and Technology, v. 30, n. 1, p. 185-194

HVITVED-JACOBSEN, T.; VOLLERTSEN, J.; NIELSEN, A.H. (2002) Sewer processes: microbial and chemical process engineering of sewer networks. Boca Raton, Fl, Estados Unidos: CRC Press, 130p

JAMEEL, P. (1989) Use of ferrous chloride to control dissolved sulfides in interceptor sewers. Journal (Water Pollution Control Federation), v. 61, n. 2, p. 230-236.

JIANG, G.; GUTIERREZ, O.; SHARMA, K.R.; KELLER, J.; YUAN, Z. (2O11) Optimization of intermittent, simultaneous dosage of nitrite and hydrochloric acid to control sulfide and methane productions in sewers. Water Research, v. 45, n. 18, p. 6163-6172. 
JIANG, G.; GUTIERREZ, O.; YUAN, Z. (2O11) The strong biocidal effect of free nitrous acid on anaerobic sewer biofilms. Water Research, v. 45, n. 12 , p. $3735-3743$.

JIANG, G.; SHARMA, K.R.; YUAN, Z. (2O13) Effects of nitrate dosing on methanogenic activity in a sulfide-producing sewer biofilm reactor. Water Research, v. 47, n. 5, p. 1783-1792.

JOBBAGY, A.; SZANTO, I.; VARGA, G.I.; SIMON, J. (1994) Sewer system odour control in the Lake Balaton area. Water Science and Technology, v. 30, p. 195-204.

KENNES, C. \& VEIGA, M.C. (2001) Bioreactors for waste gas treatment. Dordrecht: Kluwer Academic Publishers. 312p.

KOHL, A. \& NIELSEN, R. (1997) Gas purification. 5. ed. Houston: Gulf Publishing Company. 1395p.

LAHAV, O.; RITVO, G.; SLIJPER, I.; HEARNE, G.; COCHVA, M. (2004) The potential of using iron-oxide-rich soils for minimizing the detrimental effects of $\mathrm{H}_{2} \mathrm{~S}$ in aquaculture systems. Aquaculture, v. 238, n. 1-4, p. 263-281.

LILIAMTIS, T.B. (2007) Avaliação da adição de nitrato de amônio para redução de odor nos esgotos de Pereira Barreto-SP: reflexos na qualidade da água do reservatório de Três Irmãos, após dez anos de aplicação. 147f. Tese (Doutorado em Saúde Pública) - Faculdade de Saúde Pública, Universidade de São Paulo, São Paulo.

MATOS, J.S. \& AIRES, C.M. (1995) Mathematical modeling of sulphides and hydrogen sulphide gas build-up in the cosas do estoril sewerage system. Water Science and Technology, v. 31, n. 7 , p. 255-261.

MCGINNIS, D.F. \& LITTLE, J.C. (1998) Bubble dynamics and oxygen transfer in a speece cone. Water Science and Technology, v. 37, n. 2, p. 285-292.

METCALF \& EDDY, B.; TCHOBANOGLOUS, G. (2004) Wastewater engineering: treatment, disposal, reuse. 4. ed. New York: McGraw-Hill. 1819p.

MOORE, L.W. (2003) Need relief: magnesium hydroxide may be the solution to your hydrogen sulfide woes. Water Environment \& Technology, v. 15, n. 10, p. 32-35.

NIELSEN, A.H.; HVITVED-JACOBSEN, T; VOLLERTSEN, J. (2005) Kinetics and stoichiometry of sulfide oxidation by sewer biofilms. Water Research, v. 39, n. 17, p. 4119-4125.

NIELSEN, A.H.; VOLLERTSEN, J.; HVITVED-JACOBSEN, T. (2003) Determination of kinetics and stoichiometry of chemical sulfide oxidation in wastewater of sewer networks. Environmental Science \& Technology, v. 37, p. 3853-3858.

OCHI, T:; KITAGAWA, M.; TANAKA, S. (1998) Controlling sulfide generation in force mains by air injection. Water Science and Technology, v. 37, n. 1, p. 87-95.

PADIVAL, N.A.; KIMBELL, W.A.; REDNER, J.A. (1995) Use of iron salts to control dissolved sulfide in trunk sewers. Journal of Environmental Engineering, v. 121, n. 11, p. 824-829.
PAGLIUSO, J.D:; PASSIG, F.H.; VILLELA, L.C.H. (2002) Odour treatment and energy recovery in anaerobic sewage treatment plants. In: Oficina e Simpósio Latino-americano de Digestão Anaeróbia, 7. Anais... México: IWA/FEMISCA.

PARK, K.; LEE, H.; PHELAN, S.; LIYANAARACHCHI, S.; MARLENI, N.; NAVARATNA, D.; JEGATHEESAN, V.; SHU, L. (2014) Mitigation strategies of hydrogen sulphide emission in sewer networks: a review. International Biodeterioration \& Biodegradation, v. 95, Part A, p. 251-261.

POULTON, S.W.; KROM, M.D.; RIJN, J.V.; RAISWELL, R. (2002) The use of hydrous iron (III) oxides for the removal of hydrogen sulphide in aqueous systems. Water Research, v. 36, n. 4. p. 825-834.

RODRIGUEZ-GOMEZ, L.E.; DELGADO, S.; ALVAREZ, M.; ELMALEH S. (2005) Inhibition of sulfide generation in a reclaimed wastewater pipe by nitrate dosage and denitrification kinetics. Water Environment Research, v. 77, p. 193-198.

ROSSIN, A.C.; SANTOS, C.L.; SIQUEIRA, J.E.C.; MANCUSO, P.C.S. (1989) Aplicação de nitrato de amônio para o controle de odor na rede de esgotos de Santos e São Vicente. In: Congresso Brasileiro de Engenharia Sanitária e Ambiental, 15. Anais... Rio de Janeiro: ABES. p. 455-468.

SERCOMBE, D.C.W. (1995) The control of septicity and odours in sewerage systems and at sewage treatment works operated by anglian water services limited. Water Science and Technology, v. 31, n. 7. p. 283-292.

SILVA, M.B.; LECHI, R.A.L; SILVA, H.P.M.; GONÇALVES, R.F. (2007) Comparação do desempenho de diferentes filtros biológicos na remoção de H2S do ar em estações de tratamento de esgoto sanitário. In: Congresso Brasileiro de Engenharia Sanitária e Ambiental, 24. Anais... Belo Horizonte: ABES.

SOUZA, C.L. (2010) Estudo das rotas de formação, transporte e consumo dos gases metano e sulfeto de hidrogênio resultantes do tratamento de esgoto doméstico em reatores UASB. 127f. Tese (Doutorado em Saneamento, Meio Ambiente e Recursos Hídricos) - Escola de Engenharia, Universidade Federal de Minas Gerais, Belo Horizonte.

SOUZA, C.L.; CHERNICHARO, C.A.L.; MELO, G.C.B. (2010) Methane and hydrogen sulfide emissions in UASB reactors treating domestic wastewater. In: Congress on Anaerobic Digestion, 12. Anais... México: IWA.

STUETZ, R.M. \& FRECHEN, F.B. (2001) Odours in wastewater treatment: measurement, modelling and control. Londres: IWA Publishing. 456p.

SUN, J.; PIKAAR, I.; SHARMA, K.R.; KELLER, J.; YUAN, Z. (2O15) Feasibility of sulfide control in sewers by reuse of iron rich drinking water treatment sludge. Water Research, v. 71, p. 150-159.

TANAKA, N.; HVITVED-JACOBSEN, T;; OCHI, T.; SATO, N. (2000) Aerobic-anaerobic microbial wastewater transformations and reaeration in an air-injected pressure sewer. Water Environment Research, v. 72, p. 665-674. 
TANAKA, N. \& TAKENAKA, K. (1995) Control of hydrogen sulfide and degradation of organic matter by air injection into a wastewater force main. Water Science and Technology, v. 31, n. 7, p. 273-282.

TOMAR, M. \& ABDULLAH, T.H.A. (1994) Evaluation of chemicals to control the generation of malodorous hydrogen sulfide in waste water. Water Research, v. 28, n. 12, p. 2545-2552.

USEPA - Agência de Proteção Ambiental dos Estados Unidos. (1985) Design manual: odor and corrosion control in sanitary sewerage systems and treatment plants. Washington, D.C.: Center for Environmental Research Information. 132p.

USEPA - Agência de Proteção Ambiental dos Estados Unidos. (1991) Hydrogen sulphide corrosion in wastewater collection and treatment system. Report to Congress. Technical Report. Washington, D.C.: Office of Water. 141 p.

VAN DURME, G.P. \& BERKENPAS, K.J. (1989) Comparing sulfide control products. Operational Forum, v. 6, n. 2, p. 12-19.

WALTRIP, D. \& SNYDER, E.G. (1985) Elimination of odor at six major wastewater treatment plants. Journal (Water Pollution Control Federation), v. 57, n. 10, p. 1027-1032.
WEF - Water Environment Federation. (1995) Odor control in wastewater treatment plants: manual of practice no. 22. Alexandria: Water Environment Federation. $282 \mathrm{p}$.

WEF - Water Environment Federation. (2004) Control of odors and emissions from wastewater treatment plants: manual of practice 25. Alexandria: Water Environment Federation. 566 p.

WEI, D. \& OSSEO-ASARE, K. (1995) Formation of iron monosulfide: a spectrophotometric study of the reaction between ferrous and sulfide ions in aqueous solutions. Journal of Colloid and Interface Science, v. 174, n. 2, p. 273-282.

WERF - Water Environment and Reuse Foundation. (2007) Minimization of odors and corrosion in collection systems (phase 1). Report O4-CTS-1. Alexandria: Water Environment Research Foundation. 232 p.

YANG, W.; VOLLERTSEN, J.; HVITVED-JACOBSEN, T. (2O05) Anoxic sulfide oxidation in wastewater of sewer networks. Water Science and Technology, v. 52, n. 3, p. 191-199.

ZHANG, L.; DE SCHRYVER, P.; DE GUSSEME, B.; DE MUYNCK, W.; BOON, N.; VERSTRAETE, W. (2008) Chemical and biological technologies for hydrogen sulfide emission control in sewer systems: a review. Water Research, v. 42, n. 1-2, p. 1-12. 